\title{
Determination of Adrenosterone and its Metabolites in Human Urine by LC/APCI/MS and GC/MS
}

\author{
Eunjung Han, ${ }^{\dagger \neq}$ Okkyoung Yim, ${ }^{\ddagger}$ Sun-young Beak ${ }^{\dagger}$ Jaeyeon Chung, ${ }^{\ddagger}$ Ji-hye Lee, ${ }^{\dagger}$ Jungahn Kim, and Yunje Kim ${ }^{\ddagger *}$ \\ -Korea Institute of Science and Technologv, P. O. Box 131. Cheongrvang, Seoul 136-791, Korea. "E-mail: wkimakist.re.kr \\ ${ }^{\ddagger}$ Department of Chemistrv, Kunghee Lniversity. Seoul 130-701, Korea \\ Received Harch 16, 2009, Accepted Hav 11, 2009
}

\begin{abstract}
This study was done for the detennination and excretion profile of adrenosterone and its metabolites in human urine using both liquid chromatography with atmospheric pressure chemical ionization mass spectrometry and gas chronatography with mass spectrometry. Adrenosterone and its two metabolites were detected in human urine after administration a healthy volunteer with $75 \mathrm{mg}$ of adrenosterone. We found that adrenosterone- $\mathrm{Ml}\left(\mathrm{C}_{10} \mathrm{H}_{20} \mathrm{O}_{3}\right)$ was a reduction and adrenosterone- $\mathrm{M} 2\left(\mathrm{C}_{19} \mathrm{H}_{20} \mathrm{O}_{4}\right)$ was a hydroxylation at $\mathrm{C}$-ring, which did not know the exact position of the C-ring. The adrenosterone parent was detected by GC/TOF-MS, but not detected by LC/APCI/MS because of low intensity. Adrenosterone and its two metabolites were excreted as their glucuronided fractions. The recovery of this method ranged from 100.7 to $118.4 \%$ and the reproducibility and accuracy test were 85.5 to $112.0 \%$ and 1.1 to $8.4 \%$, respectively. The excretion studies showed that adrenosterone and its metabolites were detectable in human urine during a $48 \mathrm{~h}$ period after oral administration, with maximum level of excretion at $4.1 \mathrm{~h}$. The glucuro-/sulfaconjugated ratio of adrenosterone, MI and M2 was $0.73 \pm 0.03,0.96 \pm 0.06$ and $0.89 \pm 0.03(n=6)$, respectively. The anounts of adrenosterone excreted in urine were $14.75 \mathrm{ng}$ for $48 \mathrm{~h}$. Also, the maximum level of androsterone and $11 \beta$-hydroxy androsterone, which were endogenous steroids, were reached $4.1 \mathrm{~h}$ after the oral administration of adrenosterone.
\end{abstract}

Key Words: Adrenosterone, Metabolites, LC/APCI/MS, GC/MS

\section{Introduction}

Anabolic-androgenic steroids (AAS) have been widely used as therapeutic agents for restoring muscle strength and increasing muscle size. ${ }^{1.2}$ However. abuse of AAS causes many adverse effects in several organs șystems. particularly the liver and heart. ${ }^{3.4}$

Over the last decade. a number of certain type of anabolic steroids. so called prohormones. have become available in the United States as nutritional supplements. "The term "prohormone" is used because initially these substances were precursors of testosterone (T) or nortestosterone. These products Supplement Health and Education Act. although the recently are sold as over-the-counter products under the 1994 Dietary signed "Anabolic steroid Control Act of 2004" is intended to put a ban on these substances. Global distribution via the internet has resulted in a huge international commercial success for products including androst-4-ene-3,17-dione (AD), 19-norandrostenedione and dehydroepiandrosterone. The use of these substances constitutes a doping offence according to the regulations ${ }^{6}$ of the World Anti-Doping Agency (WADA).

In general. adrenosterone (androst-4-ene-3.11.17-trione. Fig. 1). a tri-ketosteroid. was isolated from the cortical extracts by Reichstein. Adrenosterone exhibits a variety of biological properties such as androgenic properties and activities. ${ }^{8.9}$ It also possesses aromatase (estrogen synthetase) inhibitory activity which play's an important role managing the estrogenmediated events especially in ovulation and the growth of estrogen-dependent tumors. ${ }^{\text {li }}$

Generally. metabolites in urine are polar. so it is not easy' to use gas chromatography/mass spectrometry (GC/MS) without derivatization for their analy sis. ${ }^{11-14}$ More recently, liquid chromatography/mass spectronetry (LC/MS) has been used for trace bioanaly'sis. ${ }^{15-18}$ This technique allows highly' sensitive determinations without derivatization as required for GC/MS. It is also possible to devise methods in specificity for metabolites and structurally similar compounds. ${ }^{19}$

The present work reports a method to detect the metabolites of adrenosterone in human urine after oral administration. using both $\mathrm{LC} / \mathrm{MS}$ and GC/MS as methods for screening and confirmation. The determination of the adrenosterone parent and its metabolites in human urine was also studied. In addition. we studied the excretion profile of adrenosterone and its metabolites after oral administration.

\section{Experimental}

Chemicals. Adrenosterone (androst-t-ene-3.11.17-trione) and 17-methyltestosterone (used as an internal standard) were purchased from Sigma Chenical Co. (MO. USA). Adrenosteorne tablets were purchased from Ergopharm (Champaign. IL, USA). Serdolite ${ }^{\text {E' }}$ PAD-1 resin (particle size 0.1-0.2 mm) was supplied by Serva Co. (Heidelberg. Germany) and was washed with acetone. methanol and distilled water before use. $\mathrm{KH}_{2} \mathrm{PO}_{4}$ and $\mathrm{K}_{3} \mathrm{PO}_{4}$ were obtained from KANTO Chemical Co (Tokyo. Japan). $\beta$-Glucuronidase was obtained from Roche Diagnostics (Mannheim. Gernany). Diethyl ether and acetonitrile were purchased from J. T. Baker (Phillipsburg. MT. USA). Anmonium acetate was purchased from YAKURY Chemical Co (Tokyo. Japan). Acetonitrile and distilled water were used after filtering through Millipore filters $(0.45 \mu \mathrm{m}$. MA, USA) and sonication for $20 \mathrm{~min}$. $N$-Methy $1-\mathrm{N}$-trimethyl- 
Table 1. Operating conditions for LC/APCIMS

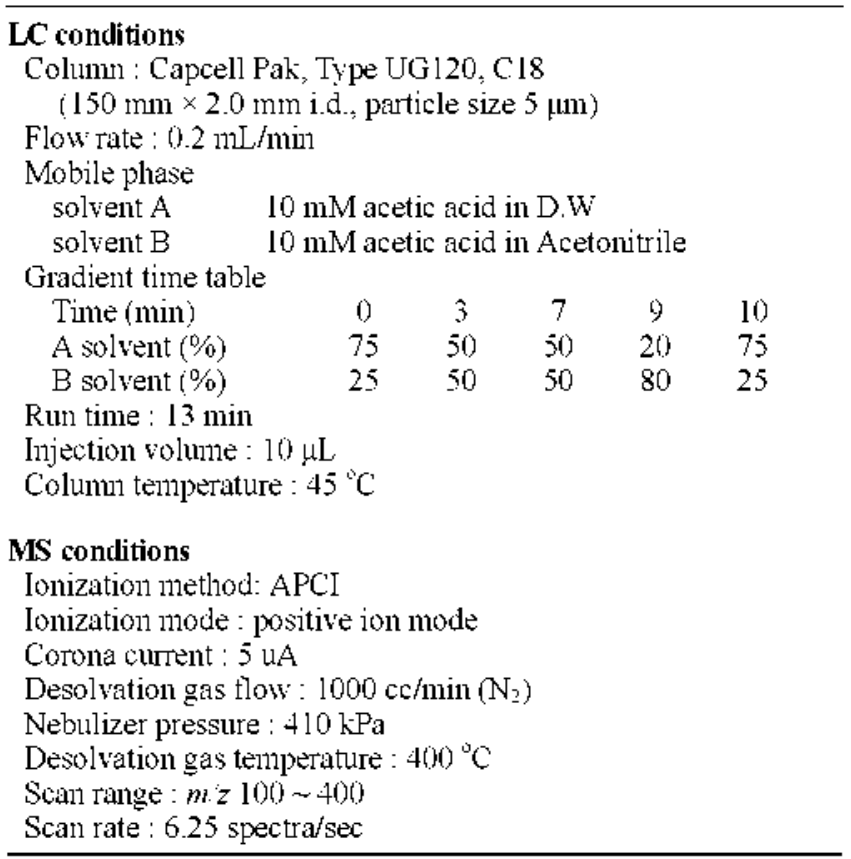

sily ltrifluoroacetamide (MSTFA), ammonium iodide $\left(\mathrm{NH}_{4} \mathrm{I}\right)$ and dithioent thritol (DTE) were obtained from Sigma.

Instruments and equipment. The LC/TOF-MS sy stem. consisted of an HP 1100 series LC with an atmospheric pressure chemical ionization (APCI) source from Agilent Technologies (Palo Alto. CA USA) and TOF-MS from LECO (St. Joseph. MI. USA), was used for the separation and estimation of the molecular weights of metabolites. Liquid chromatographic separation was done on a Capcell Pak $\mathrm{C}_{18}$ column ( $150 \mathrm{~mm} \times$ $2.0 \mathrm{~mm}$ i.d. particle size $5 \mu \mathrm{m}$ ) from Shiseido (Chuoku, Japan). The $6890 \mathrm{~N}$ GC from Agilent with TOF-MS from LECO was used to detect suspected metabolites. $6890 \mathrm{~N}$ GC $-5975 \mathrm{MSD}$ from Agilent was used for the excretion studies for adrenosterone and its urinary metabolites. The column was an Ultra- 2 cross-linked $5 \%$ phenylmethy lsiloxane capillary column ( $25 \mathrm{~m} \times 0.2 \mathrm{~mm}$ i.d. $0.11 \mu \mathrm{m}$ film thickness). Operating conditions for LC/APCI/MS and GC/MS are shown in Tables 1 and 2. respectively

HS501D shaker from IKA (Staufen, Germany) for liquid extraction, Varifuge-F from Heraeus (Hanau, Germany) for centrifugation, vortex mixer from Scientific Industry (Bohemia, USA), Turbovap ${ }^{\text {E }}$ LV evaporator from Zymark (Hopkinton. MA. USA) and WB 2000 evaporator from Hiedolph (Schwabach Germany) for sample concentration. and ecoline RE112 Freezer from LAUDA (Lauda-Könogshofen Germany) to take organic laỵer from extraction procedure were used.

Volumteersample. A healthy male volunteer (age 30, weight $75 \mathrm{~kg}$ ) was orally dosed with one tablet of 11-0.5o (trade name) which included adrenosterone $75 \mathrm{mg}$. Urine samples were collected to 49 h $(1.1 .5,2.2 .4 .1,5,11.16 .5 .18 .31,49 \mathrm{~h})$ and were kept at $2-3{ }^{\circ} \mathrm{C}$

Sample preparation. The extraction was based on a method described for anabolic steroids in doping control test procedure $^{2 i 21}$ A Pasteur pipette was filled with Aqueous Serdolite ${ }^{B}$
Table 2. Operating conditions for GC/MS

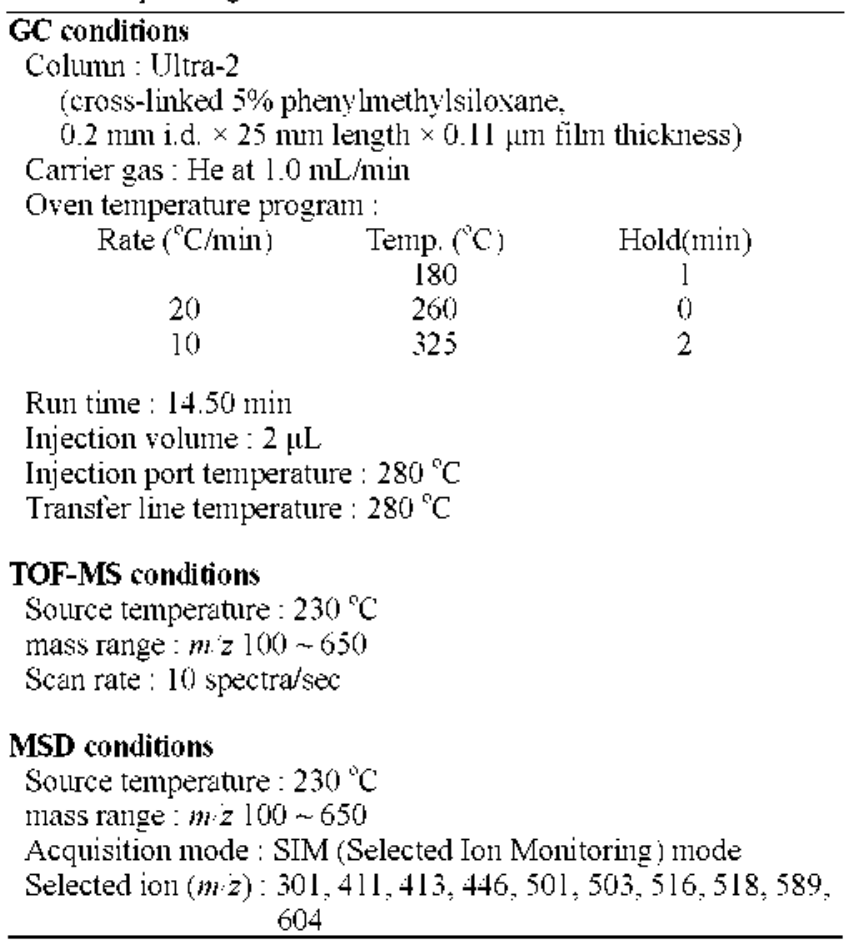

PAD- 1 resin until a bead height of $1.5 \mathrm{~cm}$ was achieved. The column was washed with $2 \mathrm{~mL}$ of distilled water and then 3 $\mathrm{mL}$ of a urine sample spiked with 17 -methyltestosterone $(50 \mu \mathrm{L}$, $10 \mu \mathrm{g} \mathrm{mL}^{-1}$ ) as the internal standard was passed through the column. The adsorbed sanple was washed with $2 \mathrm{~nL}$ of distilled water and eluted with $+\mathrm{mL}$ of methanol. The collected solution was evaporated with a rotary evaporator, and the residue was dissolved in $1 \mathrm{~mL}$ of phosplate buffer $(0.2 \mathrm{M}$. $\mathrm{pH}$ 6.8).

$\beta$-Glucuronidase $(50 \mu \mathrm{L})$ was added and the solution was heated at $55^{\circ} \mathrm{C}$ for $1 \mathrm{~h}$ in order to hydrolyze the glucuronide conjugate. After hydrolysis and cooling to room temperature, $5 \mathrm{~mL}$ of ether was added and then the mixture was shaken for $10 \mathrm{~min}$ and centrifuged at $2500 \mathrm{rpm}$ for $5 \mathrm{~min}$. The organic layer was transferred to another test tube and then concentrated at $40^{\circ} \mathrm{C}$ under a gentle stream of nitrogen. The residue was dissolved in $100 \mu \mathrm{L}$ of methanol. and $10 \mu \mathrm{L}$ was injected into the $\mathrm{LC} / \mathrm{APCI} / \mathrm{MS}$.

The ratio of free. glucuro- and sulfa-conjugaed forms of adrenosterone and its metabolites were studied to the excreted forms.

Trimethylsilylation for GC/MS. For characterization of adrenosterone and its urinary metabolites proposed by $\mathrm{GC} / \mathrm{MS}$. the residue was dried in a vacuun desiccator for 30 nuin. The dried residue was dissolved in $50 \mu \mathrm{L}$ of MSTFA/NH $\mathrm{N}_{4} / \mathrm{DTE}$ $(500: 4: 2, \mathrm{w} / \mathrm{w} / \mathrm{w})$ and the solutions was heated for $30 \mathrm{~min}$ at $70^{\circ} \mathrm{C}$. Two $\mu \mathrm{L}$ was injected into the GC/MS, , $^{2,23}$

Method validation. For a calibration curve of adrenosterone. the proper amount of standard and internal standard to $1,2,5$. 10 and $20 \mathrm{ng} \mathrm{mL}^{-1}$ were fortified into the $3 \mathrm{~mL}$ blank urine and used for GC/MSD after trimethy lsilylation.

The accuracy. recovery and reproducibility of this method were tested at three levels $\left(1.20 .50 \mathrm{ng} \mathrm{mL}^{-1}\right)$ for adrenosterone. 
The $3 \mathrm{~mL}$ blank urines $(\mathrm{n}=6$ ) were spiked standard and internal standard at three levels $\left(1,20.50 \mathrm{ng} \mathrm{mL} L^{-1}\right)$ and used for $\mathrm{GC} / \mathrm{MSD}$ after trimethy lsilylation.

\section{Results and Discussion}

Determination of adrenostemne and its metalolites by $\mathbf{L C} /$ APCI/MS. The molecular mass of adrenosterone is $300 \mathrm{Da}$ and its structure is shown in Figure 1. The urine sample extracts were analyzed by LC/APCI/MS. Figure 2 shows total ion chromatograms (TICs) of standard, blank urine, spiked urine and dosed urine. which is the urine of $4.10 \mathrm{~h}$ after oral administration. by LC/APCI/MS. Two unknown peaks desig-

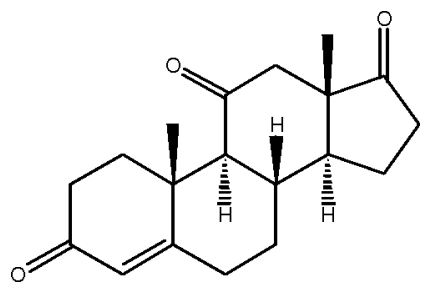

Figure 1. Structure of adrenosterone.

(a) Standard

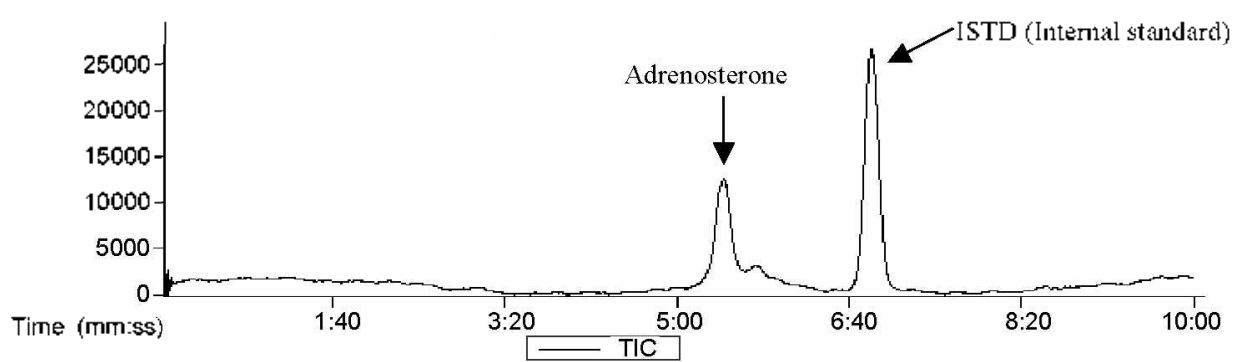

(b) Blank urine

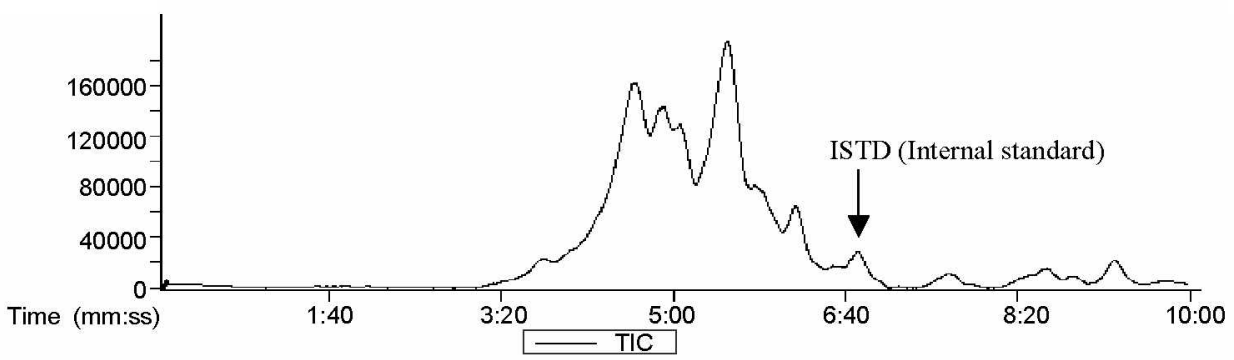

(c) Spiked unine

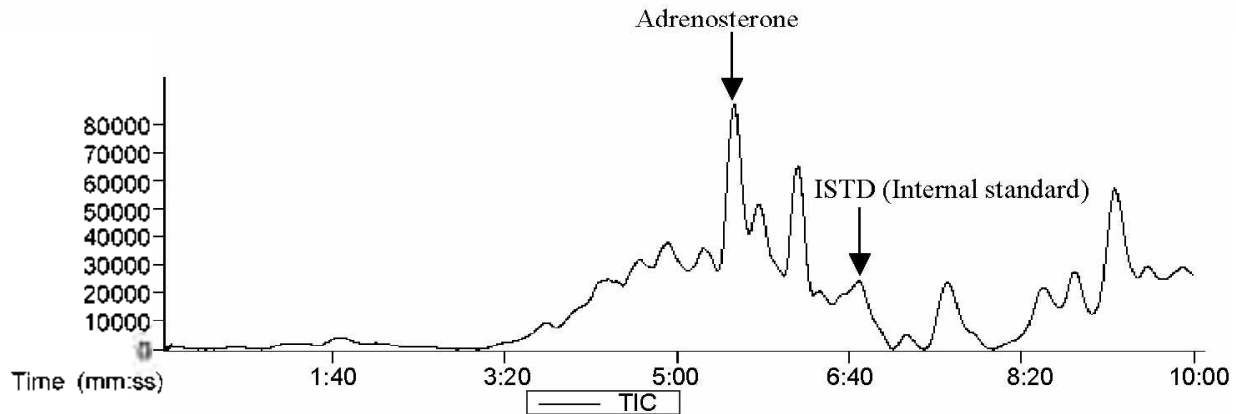

(d) Dosed urine

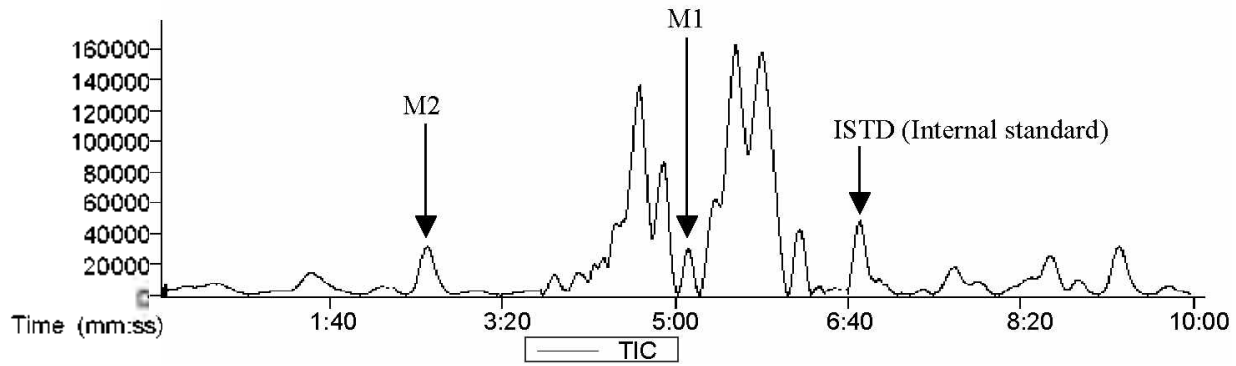

Figure 2. Total ion chromatograms of (a) standard ( $10 \mu \mathrm{g} / \mathrm{mL}$ ), (b) blank urine, (c) spiked urine at $10 \mu \mathrm{g} / \mathrm{mL}$, and (d) dosed urine after the oral administration of adrenosterone showing adrenosterone-M1 and M2 peaks by LC/APCI/MS. 
(a) Blank urine ( $m z$ 303)

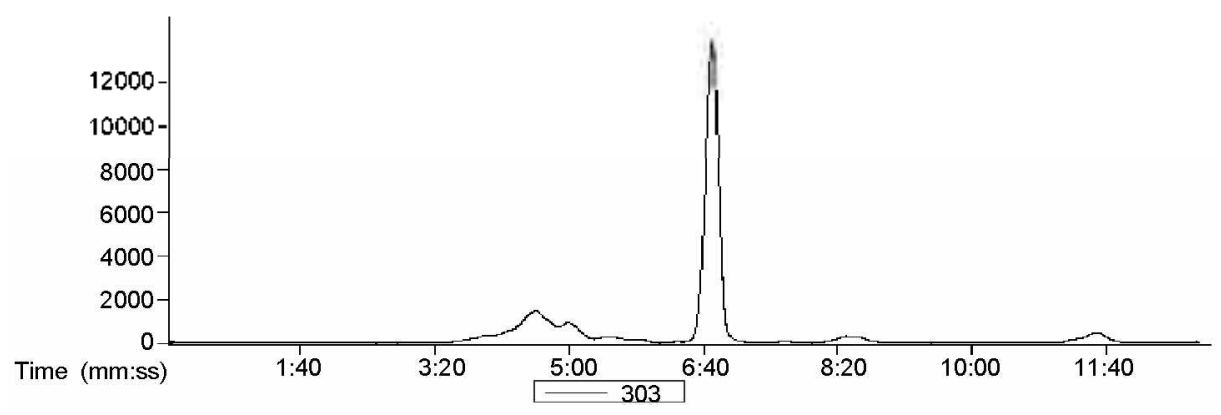

(b) Dosed urine (mz 303)

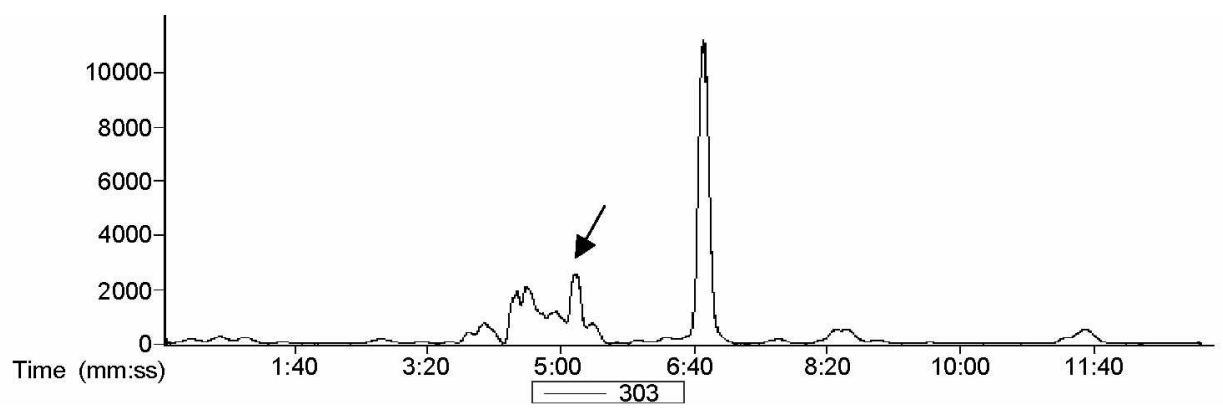

(c) Mass spectrum

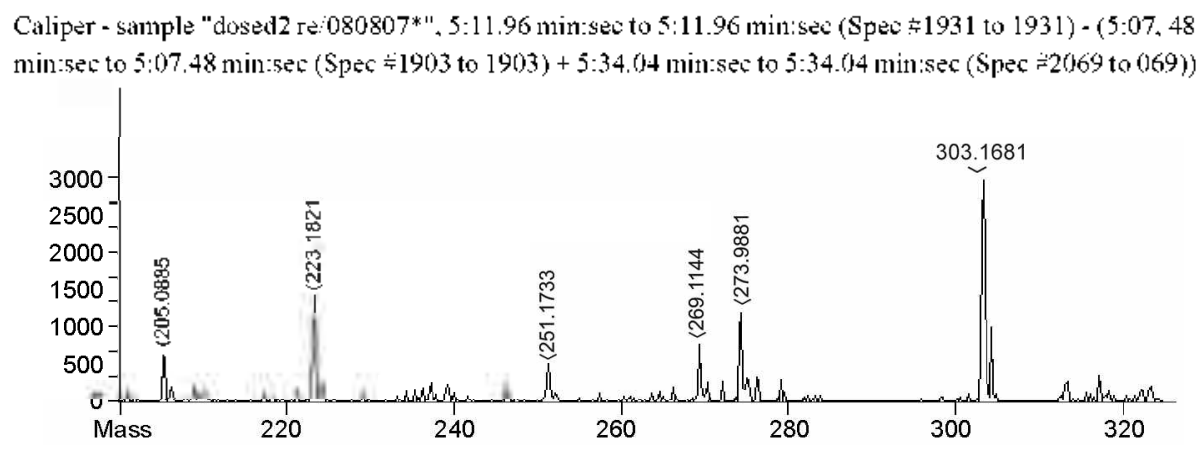

Figure 3. Extracted ion chromatograms ( $m$ z 303 ) of (a) blank urine, (b) dosed urine showing adrenosterone-MI peak (c) mass spectrum corresponding to adrenosterone-Ml.

nated adrenosterone-MI (5.11 min) and adrenosterone-M2 (2.40 $\mathrm{min}$ ) detected before adrenosterone elution ( $5.26 \mathrm{~min}$ ). Figures 3 and 4 show the extracted ion chromatograms (EICs) of $m z 303$ and 317 for blank urine and dosed urine and the mass spectra of adrenosterone-M1 and adrenosteroen-M2. respectively: From these results. we suggest that adrenosterone-M1 and $\mathrm{M} 2$ have $m / z 302\left(\mathrm{C}_{19} \mathrm{H}_{26} \mathrm{O}_{3}\right)$ and $316\left(\mathrm{C}_{1} \mathrm{H}_{2}\right.$ $\left.\mathrm{O}_{4}\right)$ as molecular ions. respectively: We checked that the adrenosterone parent was not detected by LC/APCI/MS.

Charaterization of adrenosterone and its metabolites by GC/MS. The adrenosterone and its metabolites were also analyzed by GC/TOF-MS after trimethylsilylation. Figure 5 showed the mass spectra of 3TMS-adrenosterone. 3TMSadrenosterone-M1 and 4TMS-adrenosterone-M2. The mass spectrum of 3TMS-adrenosterone (Fig. 5a) showed the molecular ion at $m z 516$ and fragment ions at $m z 129,169,411$ $\left(\left[\mathrm{M}-\mathrm{CH}_{3}-\mathrm{OTMSH}\right]^{+}\right)$and $501\left(\left[\mathrm{M}-\mathrm{CH}_{3}\right]^{+}\right)$ions. The $m z \mathrm{z} 169$ ion. already well known in 17-keto steroid fragmentation. derived from the C/D-ring cleavage. The $m: z 129$ ion could be associated with the D-ring fragmentation hypothesis (confirmed by the absence of $m z 169)^{\text {?(1,2n }}$ The mass spectrum of 3TMS-adrenosterone-Ml showed the figure $5 \mathrm{~b}$. The main fragment ions of 3TMS-adrenosterone-Ml were observed at $\mathrm{m} z 503\left(\left[\mathrm{M}-\mathrm{CH}_{3}\right]^{-}\right)$and $413\left(\left[\mathrm{M}-\mathrm{CH}_{2}-\mathrm{OTMSH}\right]^{-}\right)$. The mass spectrum of 3TMS-adrenosterone-Ml contained $m z 129$ and 169 ions. We suggest that adrenosterone-Ml was a reduction with $m: z 303([\mathrm{M}+\mathrm{H}])^{+}$from LC/MS result. which did not know exact position. The mass spectrum of 4TMS-adrenosterone-M2 (Fig. $5 \mathrm{c}$ ) is characterized by the molecular ion at $m z 604$ and fragment ions at $m z 169.209$ (cleavage of C 7-8 and 9-10). 437 ([M-C/D ring $\left.]^{-}\right), 589\left(\left[\mathrm{M}-\mathrm{CH}_{3}\right]^{+}\right)$ions. $^{201}$ We could deduce that adrenosterone-M2 was substituted by one hydrosyl group on the C-ring with $m z 317([\mathrm{M}+\mathrm{H}])^{+}$from LC/MS result. which did not know exact configuration of the $\mathrm{C}$-ring. Table 4 summarized the retention time and fragnent ions for compared adrenosterone and its metabolites obtained 
(a) Blank urine ( $m$ z 317)

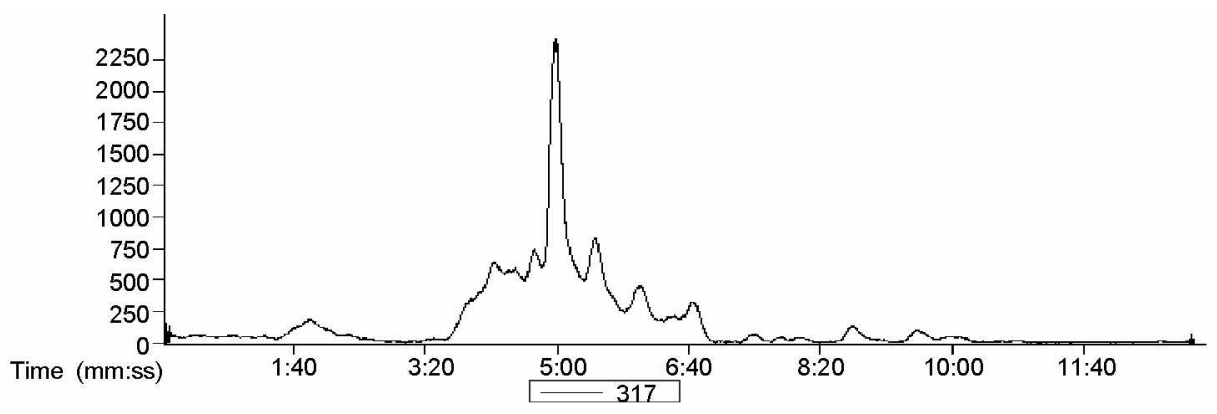

(b) Dosed urine (mz 317)

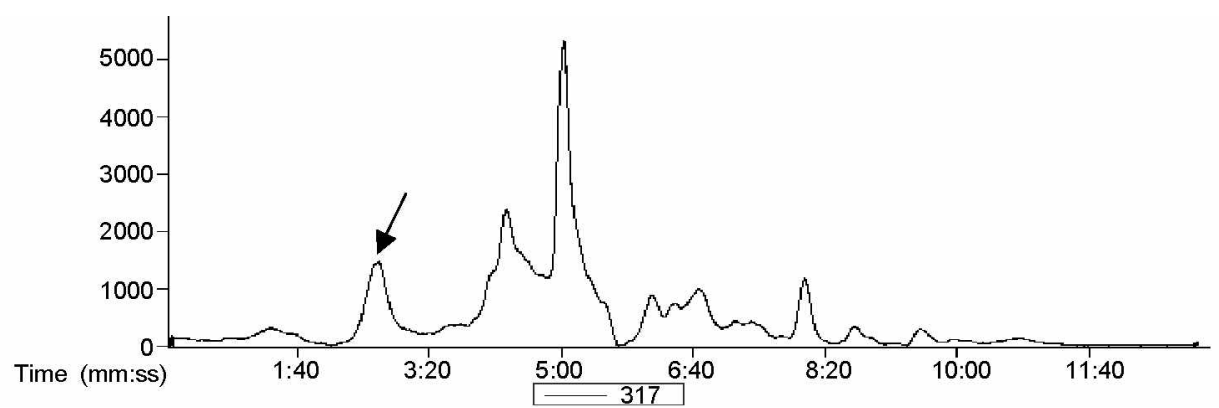

(c) Mass spectrum

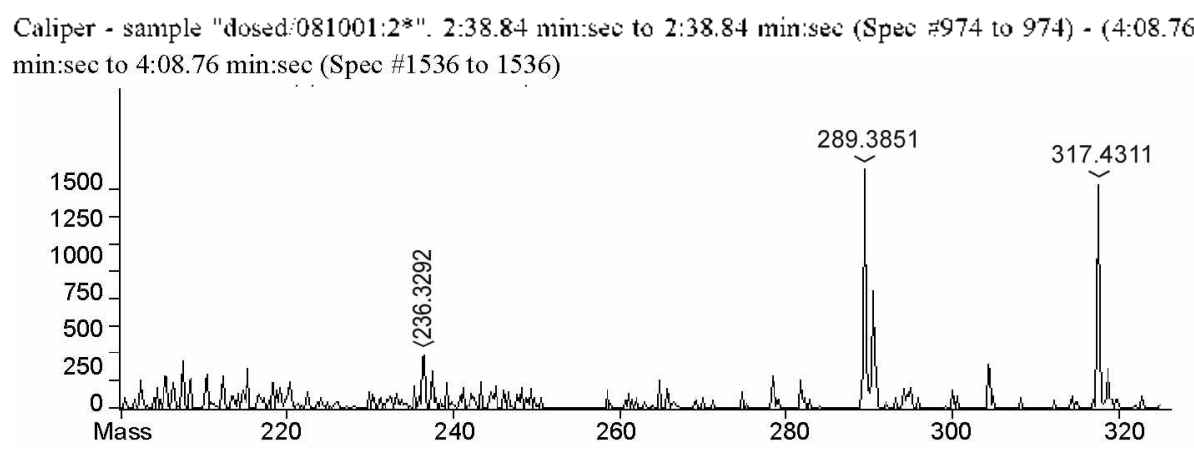

Figure 4. Extracted ion chromatograms ( $m z$ 317) of (a) blank urine, (b) dosed urine showing adrenosterone-M2 peak and (c) mass spectrum of adrenosterone-M2.

LC/APCL/MS and GC/TOF-MS. The adrenosterone parent was detected by GC/TOF-MS. but not detected by LC/APCI/ MS because of low intensity.

Method validation. The regression line was $y=0.0111 \mathrm{x}+$ 0.0077 . and correlation coefficient $\left(\mathrm{r}^{2}\right)$ was 0.9995 . The results for recovery. reproducibility and accuracy are summarized in Table 3 . As shown in Table 3 , the recovery ranged from 100.7 to $117.7 \%$. The reproducibility of this method was represented by percent relative standard deviation (RSD) at each fortification level and these values were within $10 \%$. The accuracy ranged from 85.6 to $112.0 \%$. The limit of detection (LOD) and the limit of detection quantification (LOQ) were $0.35 \mathrm{ng} \mathrm{mL}^{.3}$ and $0.7 \mathrm{ng} \mathrm{mL}^{-1}$, respectively.

Phase II metabolite study. For the determination of ratio of free. glucuro- and sulfa-conjugated forms. hydrolysis of glucuro-conjugates was experimented with $\beta$-glicuronidase from $E$. coli, whereas sulfa-conjugates was efficiently hydrolyzed by $\beta$-glucuronidase/ary lsulfatase from $H$. pomatia. To confirm the free form. we experimented without hydrolysis step. Because adrenosterone and its metabolites did not detect without hydrolysis procedure. we could suggest that adrenosterone and its metabolites were mainly excreted as conjugated form.

From these results. we could suggest that the sulfa conjugated forms and glucuro-forms were excreted in human urine. When we compared with the excreted forms of sulfaconjugation and glucuro-conjugation, the level of sulfa-conjugated fonns were higher than that of glucuro-conjugated forms in urine. The glucuro-/sulfa-conjugated ratio of adrenosterone. Ml and M2 was $0.73 \pm 0.03 .0 .96 \pm 0.06$ and $0.89 \pm$ $0.03(\mathrm{n}=6)$, respectively.

The excretion piofile of adienosteinne and its metabolites. The urinary excretion of adrenosterone and its metabolites in human urine were followed for $48 \mathrm{~h}$ after the oral administration of a $75 \mathrm{mg}$ dose of adrenosterone. The excretion profiles of adrenosterone and its metabolites from dosed urine, detected by GC/MSD, are shown in Figure 6. Adrenosterone, adreno- 
(a) Mass spectrum of 3TMS-adrenosterone

Caliper - sample "doseds (hydrolysis): 1", 8:19.98 minsee to 8:19.98 min:sec (Spec +1999 to 1999) - 8:19.28 min:sec to $8: 19.28 \mathrm{~min}: \sec (\mathrm{S}$
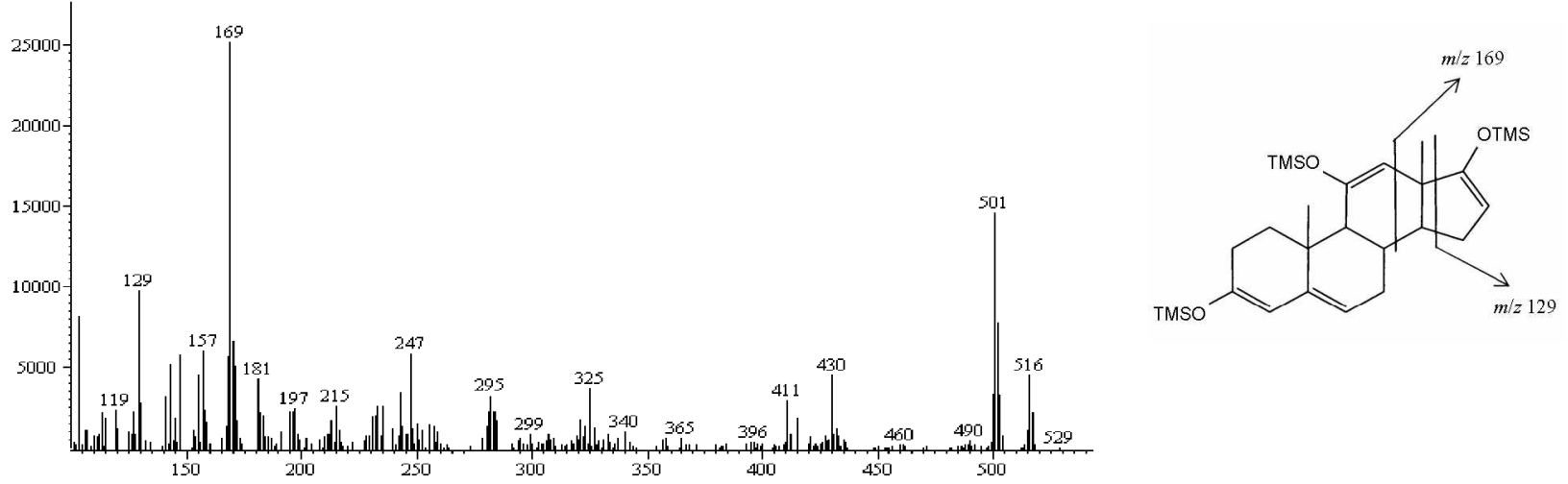

(b) Mass spectrum of 3TMS-adrenosterone-Ml

Caliper - sample "dosed5 (hydrolysis): 1", 7:20.98 min:see to 7:20.98 nin:see (Spec بُ1409 to 1409) - (5:00.08 min:sec to $5.00 .08 \mathrm{~min}: \mathrm{sec}$
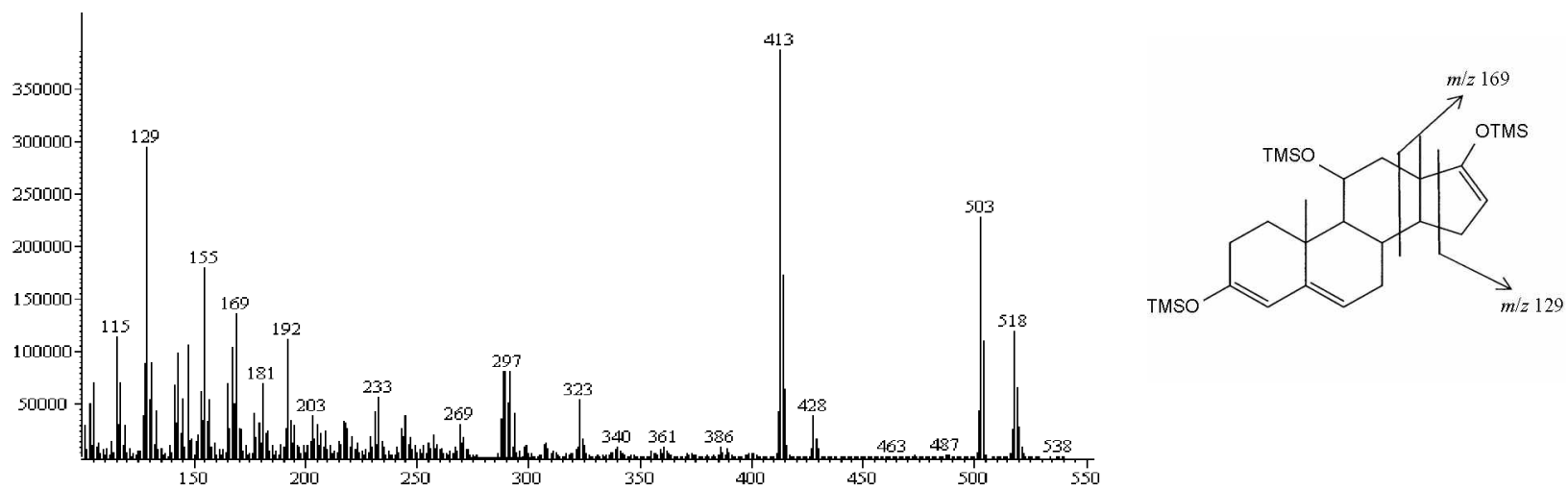

(c) Mass spectrum of 4TMS-adrenosterone-M2

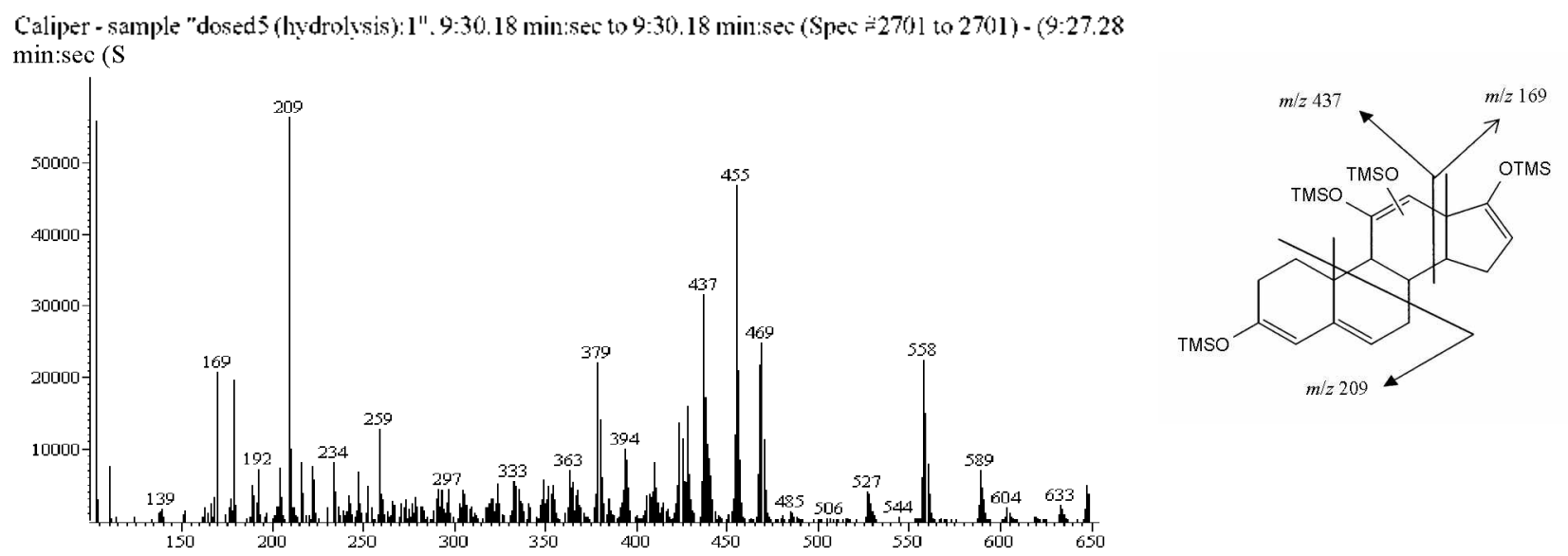

Figure 5. Mass spectra and main fragmentations of (a) 3TMS-adrenosterone, (b) 3TMS-adrenosterone-M1 and (c) 4TMS-adrenosterone-M2 by GC/TOF-MS.

Table 3. The results for recovery, reproducibility and accuracy

\begin{tabular}{|c|c|c|c|c|c|c|c|c|c|}
\hline \multirow{2}{*}{ Conc. $(n g / m L)$} & \multicolumn{3}{|c|}{ recovery } & \multicolumn{3}{|c|}{ reproducibility } & \multicolumn{3}{|c|}{ accuracy } \\
\hline & 1 & 20 & 50 & 1 & 20 & 50 & 1 & 20 & 50 \\
\hline adrenosterone & 117.7 & 108.8 & 100.7 & 2.5 & 8.4 & 3.6 & 88.4 & 85.6 & 112.0 \\
\hline
\end{tabular}


Table 4. LC/APCI/MS and GC/TOF-MS data of adrenosterone and its metabolites

\begin{tabular}{lccccccc}
\hline \multirow{2}{*}{ Compounds } & \multicolumn{2}{c}{ LC/APCI/MS } & & \multicolumn{3}{c}{ GC/TOF-MS } \\
\cline { 2 - 3 } \cline { 7 - 8 } & {$[\mathrm{M}+\mathrm{H}]^{+}$} & $\mathrm{RT}(\mathrm{mm})$ & & {$[\mathrm{M}]^{+}$} & $\mathrm{RT}(\mathrm{mm})$ & {$[\mathrm{M}-15]^{-}$} & Characteristic 1ons $(m z)$ \\
\hline adrenosterone & 301 & 5.26 & & 516 & 8.18 & 501 & 169.411 \\
adrenosterone-M1 & 303 & 5.11 & & 518 & 7.20 & 503 & 169,413 \\
adrenosterone-M2 & 316 & 2.40 & & 604 & 9.27 & 689 & $169,209.437$ \\
\hline
\end{tabular}

*RT: retention tome

(a) adrenosterone

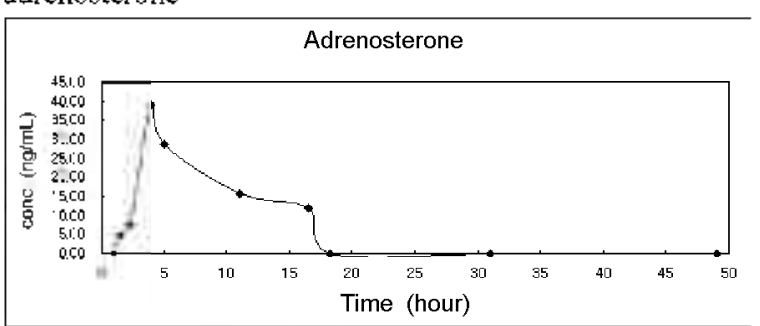

(b) aifruodetrone-MI

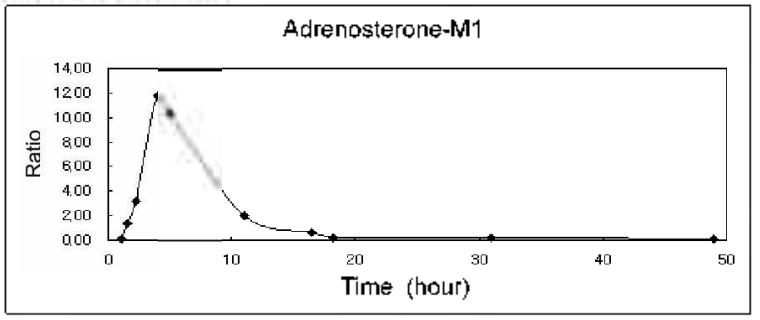

(c) adrenosterone-M2

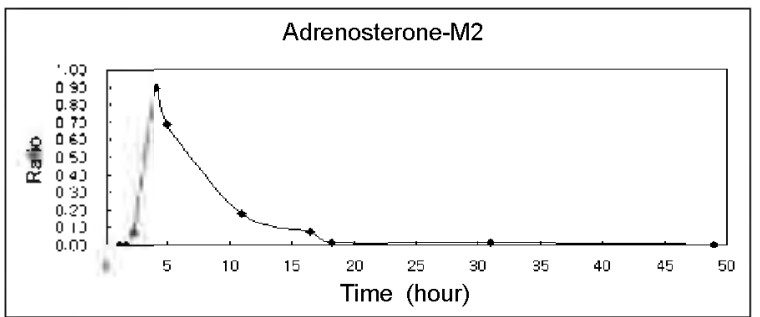

(d) androsterone

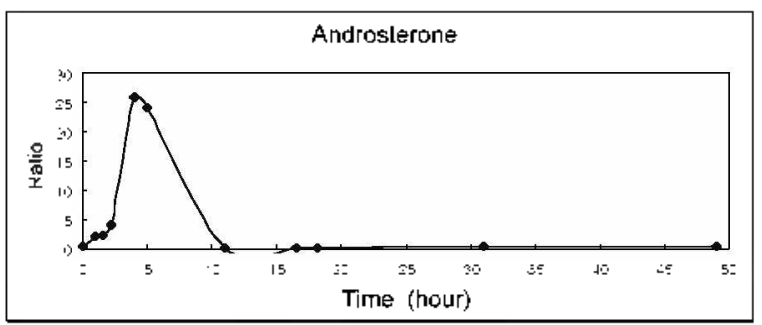

(e) 11 -hrdroxy androsterone

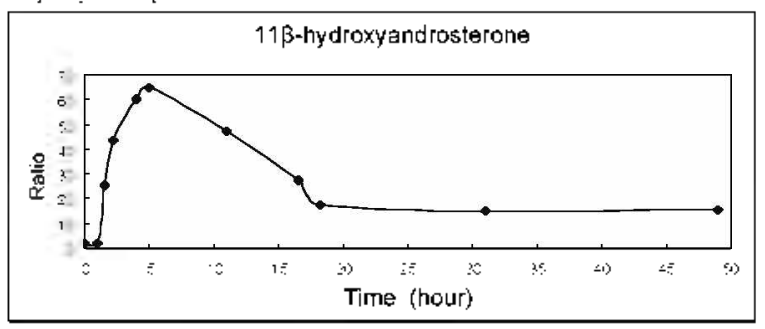

Figure 6. Excretion profiles of (a) adrenosterone, (b) adrenosterone-M1, (c) adrenosterone-M2, (d) androsterone and (e) $11 \beta$ hydroxy androsterone after the administration of adrenosterone 75 ing.
sterone-M1 and adrenosterone-M2 had a maximum level of excretion at $4.1 \mathrm{~h}$. Adrenosterone and its metabolites were no longer detectable $16 \mathrm{~h}$ after administration. because they were rapidly excreted from the body. In case of the nandrolone. it had a maximum level of excretion at $2 \mathrm{~h}$ after administration. ${ }^{24}$ Also. androsto-4-ene-3, 17-dione and boldenone reached maximum levels at $4 \mathrm{~h}$ and $5 \mathrm{~h}$ after administration. respectively. ${ }^{25.26}$ The excreted amounts from adrenosterone were $14.75 \mathrm{ng}$ for $48 \mathrm{~h}$. The half-life of adrenosterone was $5 \mathrm{~h}$ after oral adninistration. In cases of the M1 and M2 metabolites. for which no standards were available. the abundances plotted the peak area ratios of the metabolites to the internal standard.

The excretion profile of endogenous stemids after oral administration. To confirm the androgenic effects of adrenosterone. levels of six endogenous steroids (testosterone. epitestosterone. androstenone. dehydroepiandrosterone, 11 $\beta$-hy. droxy androsterone and $11 \beta$-hy'droxyetiocholanolone) in hulman urine were simultaneously analyzed by GC/MSD after oral administration. Two endogenous steroids (androsterone and $11 \beta$-hydroxy androsterone) of them were increased the level in urine flow. Figure 7 showed the excretion profiles of androsterone and $11 \beta$-hydroxy androsterone from dosed urine after oral administration. The urinary excretions of androsterone and $11 \beta$-hydroxy androsterone were increased, and the maximum urinary excretion was reached $4.1 \mathrm{~h}$. the same time as that of adrenosterone and its metabolites. As described by S. H. Lee $e t$ al. endogenous steroids levels. especially androsterone. were increased after oral administration of clostebol, mesterolone and nandrolone. ${ }^{? 7}$ In the other hand. H. R. Norli et $\mathrm{al}$. and M. Donike et al. showed that it was decreased after administration of bolasterone, norethandrolone and boldenone. $2 \times 29$

\section{Conclusions}

We have analyzed adrenosterone and its two metabolites in human urine using both LC/APCI/MS and GC/MS. As the chromatograms of the blank urine and dosed urine were compared, we found adrenosterone-MI and $\mathrm{M} 2 \mathrm{by} \mathrm{LC} / \mathrm{APCl} /$ MS. After then. we applied the GC/TOF-MS for confinnation of adrenosterone-M1 and M2 with trimethylsilylation. We suggested that adrenosterone-MI was a reduction, and adrenosterone-M2 was substituted one hydroxyl group on the Cring. The adrenosterone was detected by GC/TOF-MS. but was not detected by LC/APCI/MS because of low intensity. Adrenosterone and its metabolites were excreted as conjugated forms. Sulfa-conjugated forms were shown higher levels in urine than glucuro-conjugated forms. In the excretion profile 
studies, adrenosterone and its metabolites could be detected in urine for $48 \mathrm{~h}$ after the oral administration $(75 \mathrm{mg}$ ). and the maximum level of adrenosterone and its metabolites were observed at $4.1 \mathrm{~h}$. The amounts of adrenosterone excreted were $14.75 \mathrm{ng}$ after a $48 \mathrm{~h}$. Furthermore, the endogenous steroids. androsterone and 11 -hydroxy androsterone. reached maximum level at $4.1 \mathrm{~h}$.

\section{References}

1. Nastollah, T.: Shahidi. M. D. Clin. Ther. 2001.23, 1355

2. Kintz, P. Legal Med. 2003, 5, \$29.

3. Cellotti, F.; Negri Cesi, P.; Steroid Biochem. Afol. Biol. 1992, t3, 469 .

4. Maravelias, C.: Dona, A.: Stefanidou, M.: Spiliopoulou, G. Toxicol Lett. 2005, 158, 167.

5. Delbeke, F. T.: Van Eenoo, P.: Van Thuyne, W. I. Steroid Biochen. itol. Biol. 2003, 83, 245 .

6. WADA, The World Anti-Doping Agency, Prohibited list of substances, 2005.

7. Reichstein, T. Helv (Thim Acta 1936, 19,29.

8. Gavaco, J. E. B.: Van Blijswijk, B.; Leatherland, J. F.; Goos, H. I. T.: Schulz. R.W. Cell Tissue Res. 1999, 38, 2834.

9. Thevis, M: Opfemmann, G.: Schmickler, H: Schänzer, W. T. Mass Spectrom. 2001, 36,159.

10. Lone, K. P.; Matty, A. J. J. Fish Biol. 1981, 18, 353.

11. Yoshihama, M: Tamura, K: Nakakoshi, M.; Nakamura, J.; Fujise, N.: Kawanishi, G. J. Mass Spectrom. 2001, 36, 159.

12. Delahaut, Ph.: Tacquemin, P.: Colemonts, Y:: Dubois, M: De Graeve, J.: Deluvker, H. J. Chromatogr: B 1997, 696, 203.

13. Palermo, M.; Gomez-Sanchez, C.; Roitman, E.; Shacklenton, C.
H. Steroids 1996.61,583.

14. Kohler, K.: Par, M. K.: Opfermann, G.: Thevis, M.: Schlorer, N.: Marner, F. J.: Schänzer, W. Steroids 2007, 72, 278 .

15. Van Puymbroeck, M.; Leyssens, L.; Vanderzande, D.; Gelan, T.; Raus, J. Analvst 1998, 123, 2449

16. Raffaelli, A.; Saba, A.; Vionali, E.; Marcocci, C.; Alvadori, P.J. Chomatogr: B 2006, 830.278 .

17. Deventer, K.; Van Eenoo, P.; Mikulcikova, P.; Van Thuyne, W. Delbeke, F. T. J. Chrontatogr: B 2005, 828, 21 .

18. Mckinney, A. R.: Suann, C. T.; Dunstan, A. I.: Mulley, S. L.; Ridley, D. D.: Stenhollse, A. M. J. Chomatogr. B 2004, 811, 75.

19. Tubaro, M.; Fedrigo, M. A.; Cativiela, C.; Jimenez, A. L.; Traldi, P. Rapid Commun. Hass Spectrom. 2003, 17, 107.

20. Schanzer, W.: Donike, M. Anal Chim. Acta 1993, 275, 23

21. Hintikka, L.; Kulranne, T.: Aitio, 0.: Thevis, M.: Schänzer, W:; Kosstiainen, R. Steroids 2008, 73, 257

22. Bizec, B. L.; Courant, F.; Gaudin, I; Bichon, E.; Destres, B.; Schilt, R.; Draisci, R.; Monteau, F, Andre, F. Steroids 2006, 71 , 1078

23. Pan, M.: Zapp, J:: Becker, M.: Optenmann, G.: Bartz, U.: Schänzer, W. Steroids $2007,72,545$.

24. Torrado, S.; Segura, I.; Farre, M.; Ventura, R. Steroids 2008, 73 , 751 .

25. Deventer, K:; Van Eenoo, P.: Mikulèikova, P.: Van Thuyne, W: Delbeke, F. T. J. Chontatogr: B 2005, 828, 21 .

26. Buiarelli, F; Cartoni, G. P.; Coccioli, F; Giantetti, L.; Merolle, M. Terracciano, A. Anol Chim . Acto 2005, 552, 116.

27. Lee, S. H.: Choi, M. H.: Kim, K.: Chung. B. C. J. Kor: Chem. Soc. $1997,41,406$

28. Norli, M. R.; Esbensen. F.; Westad K.; Birkeland, I.; Hemmunersbach, P. J. Steroid Biochem. Holec. Biol. 1995, 54,83 .

29. Donike, M.: Geyer, H.: Kraft, M.: Raluth, S. Intemational ithletic Foundation: $1990 ;$ p 107 